\title{
THE RELATIONSHIP BETWEEN POSITIVE PATIENT EXPERIENCE IN ACUTE HOSPITALS AND PERSON- CENTRED CARE
}

\author{
${ }^{1}$ Randal Parlour, ${ }^{2}$ Paul Slater, ${ }^{3}$ Brendan McCormack, \\ ${ }^{4}$ Anne Gallen and ${ }^{5}$ Paula Kavanagh \\ ${ }^{1,4,5}$ Nursing and Midwifery Planning and Development, Health Service Executive, Ireland \\ ${ }^{1,2}$ Institute of Nursing and Health Research, University of Ulster, Northern Ireland \\ ${ }^{3}$ Head of Division (Nursing), Queen Margaret University, United Kingdom
}

Received 2014-08-28; Revised 2014-09-21; Accepted 2014-12-24

\begin{abstract}
Internationally, person-centred care has become a central tenet of many health and social care related policies and strategies. However, few studies exist that explicitly examine the linkage between patients' perceptions of a person-centred care climate and patients' experiences of care. This has been hampered by a dearth of instruments with acceptable psychometric properties. The aim of this study is to examine the relationship between patients' perceptions of person-centredness and their experiences of care. A cross sectional survey design was used to purposively sample $(n=345,57.5 \%)$ patients from across 10 acute hospitals settings in Ireland. The data was collected Feb 2013-May 2013. Standardised instruments were used to measure patients' perceptions of person-centredness and their experiences of care. Questionnaire packs were distributed to a sample of patients based on predetermined inclusion criteria. Completed questionnaires were returned in a sealed envelope. The instruments were psychometrically tested prior to full analysis of the results. Ethical approval was granted by Research Ethics Committees in all participating hospitals. The psychometric properties of both instruments were determined as satisfactory. There was a moderate positive and significant relationship between patients' perceptions of a person-centred climate and patient experiences. Patients who perceived care as being more personcentred also reported a more positive patient experience. The emergence of new instruments designed to measure patients' perceptions of person-centredness and patient experiences have been shown to have acceptable psychometric properties. This study demonstrates clear linkage between patients' experiences of care and the key indicators of person-centred care.
\end{abstract}

Keywords: Person-Centredness, Patient Experience, Nursing, Person-Centred Climate Questionnaire-Patients

\section{INTRODUCTION}

In this study we examine the relationship between patients' perceptions of person-centred care and their experiences of care in acute hospital settings in Ireland. Standardised instruments with proven psychometric Corresponding Author: Paul Slater, Institute of Nursing and Health Research, University of Ulster, Northern Ireland

properties were used and further tested, psychometrically, to contribute to the body of evidence on person-centred care. The Person-centred Climate Questionnaire-Patient (PCQ-P Edvardsson et al., 2008; 2009) measures the extent to which the climate (physical and psychosocial environment) is person-centred, how it supports the 
patient as a person and places them at the centre of care (Edvardsson et al., 2008). The Picker Patient Experience Questionnaire (PPE-15) is an internationally renowned instrument for measuring quality patient care (Jenkinson et al., 2003, Wolf et al., 2012). There exists a dearth of studies that have established quantitative linkage between patients' perceptions of what constitutes person-centred care and actual indicators of quality care: This study aims to address this deficit.

\subsection{Study Background}

Healthcare teams, healthcare provider organisations and governments often articulate an intention to deliver person-centred care (McCance et al., 2011). It is a central tenet in key departmental and national strategy documents such as 'Crossing the Quality Chasm' (CQHCA, 2001); the 'National Service Framework for Older People' (DH, 2001); 'Future Health: A Strategic Framework for Reform of the Health Service' (DH, 2012); and within professional organisations such as ABA (2009) and the Royal College of Nursing Principles of Nursing Practice (Principle D) which identifies the tenets of person-centred care as key indicators of quality care (Manley et al., 2011).

The evidence to support the paramount importance of person-centred care in the delivery of a quality healthcare service is slowing emerging in the research literature. Early research was hampered by poorly defined terms, small scale studies or a reliance on qualitative research methods and is of limited empirical value (Slater, 2006). In a recent systematic review of the evidence (Brownie and Nancarrow, 2013), person-centred care is reported to have a positive impact on staff job satisfaction (Lehuluante et al., 2012), staff capacity to meet the needs of patients (Brownie and Nancarrow, 2013), cost effectiveness (Olsson et al., 2009), better levels of staff autonomy and empowerment (Williams et al., 2007). For patients, significant improvements are reported in physical outcomes and reduction in boredom (Brownie and Nancarrow, 2013). However the bulk of the evidence is limited to older person settings and there are additional challenges to its implementation within acute hospital settings (Clisset et al., 2013).

The slow emergence of supporting data had been hampered by the absence of a universally accepted definition of person-centredness; the emergence of complex and difficult to test theoretical frameworks; and a dearth of specific measurement tools that would assist with strengthening the evidence base to refute or confirm theories. In recent years, within the research literature, these limitations have been addressed with a general consensus around the core tenets of a definition of person-centredness (McCormack et al., 2010) and the emergence of models of person-centred care (McCormack, 2003, McCormack and McCance 2010).

The most widely reported model of person-centred care is the Person-centred Practice Framework, developed by McCormack et al. (2011); McCormack and McCance, 2010), where they define person-centred practice as an approach to practice that is established through the formation and fostering of healthful relationships between all care providers, patients and others significant to them. It is underpinned by values of respect for persons, individual right to selfdetermination, mutual respect and understanding. The Person-centred Practice Framework is based on this definition and it encompasses three concentric rings, requisite within the care environment, in order to provide person-centred outcomes (Fig. 1). These are essentially staff relevant traits.

Central to McCormack and McCance (2010) theoretical framework is the concept of person-centred outcomes characterised by high levels of satisfaction with care, involvement with care, feelings of wellbeing and the creation of a healthful culture. Few studies have empirically demonstrated a statistical relationship between a person-centred workplace climate and the provision of person-centred outcomes. To some extent this has been caused by a lack of appropriate measurement instruments.

A critical comparative review of published tools, designed to provide measurements of person-centred care, identified 12 tools, 3 of which were specific to hospital settings (Edvardsson and Innes, 2010). One tool was identified as specific to the patient-the Person-Centred Climate Questionnaire-Patient (PCQ$P)$. The PCQ-P assesses to what extent the climate of health care settings is perceived by patients as being person-centred. It consists of 17 items measured on a 7-point likert scale designed to measure two constructs, Safety and Hospitality.

Safety is indicative of a climate where staff use understandable language, are available and approachable, appear competent, confident and respond quickly to questions. The care is provided in a clean and well-organised physical environment with the availability of both public and private spaces. 


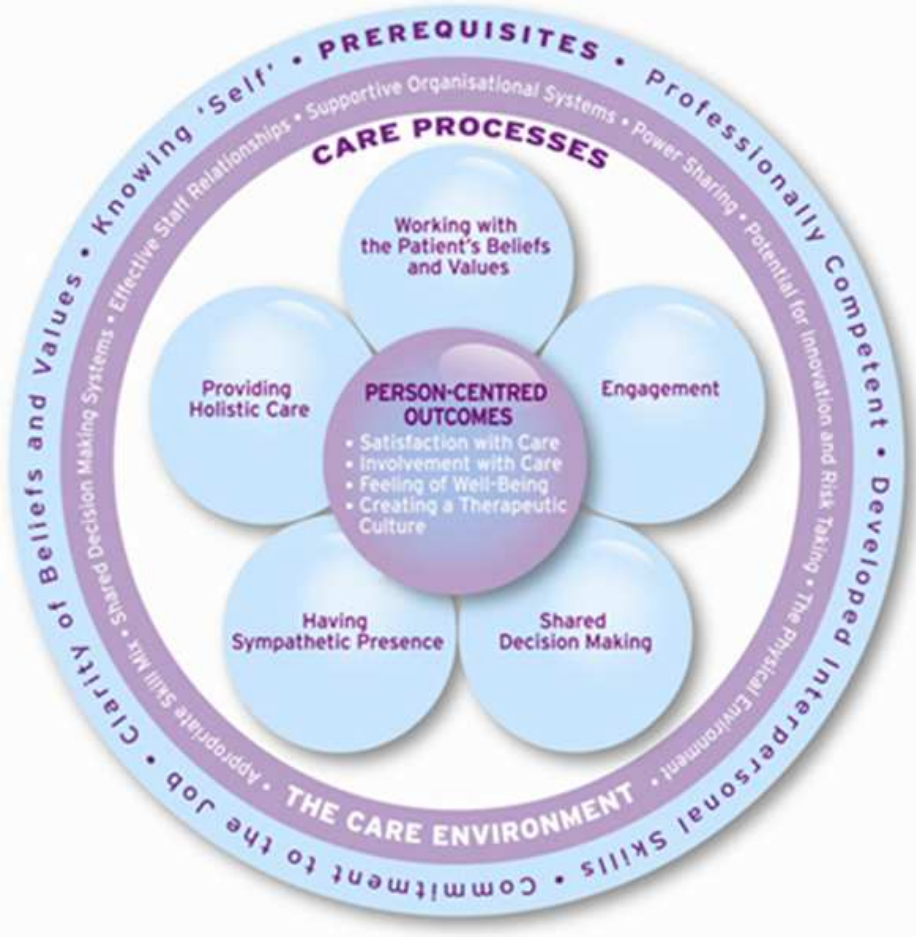

Fig. 1. Person-centred care theoretical framework

Hospitality denotes the reception and entertainment of people in the environment that conveys both feelings of being welcomed and receiving the best treatment and care. Hospitality is the presence of an environment where staff are willing to ensure the positive experience of the patients by being willing to 'do the little extra' (Edvardsson et al., 2008).

Limited evidence exists on the application of the PCQ-P in health care settings other than the applicability (Edvardsson and Innes, 2010), explanation of its theoretical background and the establishment of its psychometric properties (Edvardsson et al., 2008; 2009). This study will use the instrument to examine the perceptions of patients as regards the presence of a person-centred climate in an acute hospital setting.

For more than a decade, the picker Patient Experience Questionnaire (PPE-15) has been used to collect relevant data across countries such as Sweden, U.K., U.S.A. Switzerland and Germany and includes a sample size of almost 100,000 patients drawn from varied clinical settings. It is now an established measure of effective patient care in these countries (Jenkinson et al., 2002; Wolf et al., 2012). The psychometric properties of the PPE-15 have been established as reliable and valid (Jenkinson et al., 2002). The instrument is based on extensive qualitative research on what constitutes effective care, possesses face and content validity and has proven psychometric properties (Jenkinson et al., 2002).

Findings from relevant studies that used the PPE-15 report varied scores of 'problems with care' across countries displayed in Table 1.

\subsection{Study Purpose/Aims}

The aim of the study is to examine, within acute hospital settings in Ireland, the relationship between the patient experience and measures of the person-centred climate as perceived by patients.

The objectives are to:

- Establish the psychometric properties of two instruments designed to measure patients' experience of care and perceptions of personcentred climate

- Examine the relationship between individual scores across acute hospital settings 
Table 1. Percentage of respondents indicating a problem on each item of the PPE-15 (values shown are percentages) (adapted from Jenkinson et al., 2002)

\begin{tabular}{|c|c|c|c|c|c|c|}
\hline Statements & UK & Switzerland & Sweden & Germany & USA & Ireland \\
\hline \multicolumn{7}{|l|}{ Information and education } \\
\hline $\begin{array}{l}\text { When you had important questions } \\
\text { to ask a doctor, did you get answers } \\
\text { that you could understand? }\end{array}$ & 28.1 & 12.7 & 31.6 & 17.5 & 23.9 & 25.9 \\
\hline $\begin{array}{l}\text { When you had important questions } \\
\text { to ask a nurse, did you get answers } \\
\text { that you could understand? }\end{array}$ & 24.1 & 10.9 & 15.3 & 13.0 & 28.7 & 12.2 \\
\hline \multicolumn{7}{|l|}{ Coordination of care } \\
\hline $\begin{array}{l}\text { Sometimes in a hospital, one doctor or } \\
\text { nurse will say one thing and another will } \\
\text { say something quite different. } \\
\text { Did this happen to you? } \\
\text { Emotional comfort }\end{array}$ & 23.3 & 14.6 & 17.7 & 15.4 & 17.9 & 33.3 \\
\hline $\begin{array}{l}\text { If you had any anxieties or fears about } \\
\text { your condition or treatment, did a } \\
\text { doctor discuss them with you? }\end{array}$ & 15.1 & 5.1 & 8.2 & 11.7 & 15.9 & 24.8 \\
\hline $\begin{array}{l}\text { If you had any anxieties or fears } \\
\text { about your condition or treatment, } \\
\text { did a nurse discuss them with you? }\end{array}$ & 29.7 & 11.4 & 13.6 & 10.0 & 12.5 & 21 \\
\hline $\begin{array}{l}\text { Did you find someone on the hospital } \\
\text { staff to talk to about your concerns? }\end{array}$ & 59.3 & 35.5 & 53.3 & 45.9 & 36.9 & 20.1 \\
\hline \multicolumn{7}{|l|}{ Respect Patients preferences } \\
\hline $\begin{array}{l}\text { Did doctors talk in front of you } \\
\text { as if you weren't there? }\end{array}$ & 34.1 & 17.8 & 35.7 & 23.7 & 23.6 & 17.3 \\
\hline $\begin{array}{l}\text { Did you want to be more involved in } \\
\text { decisions made about your care and treatment? }\end{array}$ & 32.6 & 18.6 & 31.2 & 26.2 & 32.4 & 47.1 \\
\hline $\begin{array}{l}\text { Overall, did you feel you were treated with } \\
\text { respect and dignity while you were in hospital? }\end{array}$ & 30.6 & 17.6 & 28.6 & 27.6 & 33.5 & 4.2 \\
\hline \multicolumn{7}{|l|}{ Physical comfort } \\
\hline $\begin{array}{l}\text { Were you ever in pain? If yes, do you } \\
\text { Think the hospital staff did everything they } \\
\text { could to help control your pain? }\end{array}$ & 20.1 & 9.0 & 11.1 & 12.9 & 17.3 & 11.1 \\
\hline \multicolumn{7}{|l|}{ Involvement of family and friends } \\
\hline $\begin{array}{l}\text { If your family or someone else close to } \\
\text { you wanted to talk to a doctor, did they } \\
\text { have enough opportunity to do so? }\end{array}$ & 32.8 & 15.2 & 14.1 & 17.3 & 27.6 & 21.9 \\
\hline $\begin{array}{l}\text { Did the doctors or nurses give your family } \\
\text { or someone close to you all the information } \\
\text { they needed to help you recover? }\end{array}$ & 38.3 & 16.7 & 22.0 & 27.8 & 25.5 & 22.4 \\
\hline \multicolumn{7}{|l|}{ Continuity and transition } \\
\hline $\begin{array}{l}\text { Did a member of staff explain the purpose of } \\
\text { the medicines you were to take at home in a } \\
\text { way you could understand? }\end{array}$ & 23.2 & 11.1 & 16.5 & 16.5 & 13.7 & 13.7 \\
\hline $\begin{array}{l}\text { Did a member of staff tell you about medication } \\
\text { side effects to watch for when you went home? }\end{array}$ & 35.8 & 31.2 & 44.4 & 31.5 & 29.4 & 33.6 \\
\hline $\begin{array}{l}\text { Did someone tell you about danger signals } \\
\text { regarding your illness or treatment to watch } \\
\text { for after you went home? }\end{array}$ & 59.9 & 33.8 & 46.7 & 44.2 & 31.9 & 32.9 \\
\hline
\end{tabular}




\section{MATERIALS AND METHODS}

A cross sectional survey design was employed within this study. An identified staff member in each clinical setting distributed questionnaire packs to a sample of patients based upon the number of beds per ward/unit. Data was collected over a 9-month period commencing Feb 2013. Patients were asked to complete the two questionnaires either alone or with a family member and return it in a sealed envelope for collection and analysis.

\subsection{Instrumentation}

\subsubsection{The Picker Patient Experience Questionnaire}

The Picker Patient Experience Questionnaire is a 15item measure that was developed on the basis of largescale surveys in five countries (Jenkinson et al. 2002). Data from the instrument can be presented as separate scores although the primary purpose was to sum the responses to provide an overall index. Each item is coded as a dichotomous 'problem score', indicating the presence or absence of a problem. A problem is defined as an aspect of health care that could, in the eyes of the patient, be improved upon. Items considered irrelevant by patients were identified and excluded from further analysis. A mean score based on relevant data was calculated for each participant where potential scores ranged from $0 \%$-no problem to $100 \%$ total problem.

\subsubsection{The Person-Centred Climate Questionnaire-Patient}

The Person-Centred Climate Questionnaire-Patient consists of 17 items formulated as statements about the climate of the unit/ward. The items are rated on a 7-step Likert scale (ranging between $1=$ no, I disagree completely to $7=$ yes, I agree completely). The questionnaire is sum-scored and scores can range between 17 (a climate not very person-centred) to 119 (a climate very person-centred). Previous evaluation of this instrument indicated that it is a reliable and valid measure of the extent to which the climate of a health care setting is perceived as being personcentred. It has also been recognised that the scale contains items that reflect the dimensions described in the literature as being central aspects of personcentredness. The presence of both a two and three factor model has been reported in the literature
(Edvardsson et al., 2008; 2009). This study identified a two factor model (Hospitality column A, Safety column B Table 2 with acceptable measures of reliability Table 3. Factor items were aggregated to create mean factor scores (Edvardsson et al., 2008).

\subsection{Sample}

A purposive sample of 600 patients was selected from across 10 clinical settings in acute hospitals in Ireland. Site selection was based on participating sites being involved a larger study therefore the sampling frame was predetermined. This represented a broad range of clinical areas including medical, surgical, gynaecology, rheumatology and maternity.

Exclusion criteria of patients included cognitive impairment, unwilling to participate, under 18 years of age, lack of fluency in the English language, having completed the questionnaire previously. All other patients were considered relevant. A potential sampling frame of 600 patients was identified for participation in the study.

A response rate of $57.5 \%(n=345)$ was achieved. This provided a confidence interval of 3.44 at $95 \%$ confidence level. This represented orthopaedic (11\%, $\mathrm{n}=38)$, acute medicine $(18.3 \%, \mathrm{n}=63)$, gynaecology $(6.1 \%, \mathrm{n}=21)$, surgical $(3.8 \%, \mathrm{n}=13)$, medical rehabilitation $(13.9 \%, \mathrm{n}=48)$, obs gynaecology $(2.6 \%, \mathrm{n}=9)$, medicine $(12.5 \%, \mathrm{n}=43)$, rheumatology $(12.5 \%, \mathrm{n}=43)$, acute medicine $(4.1 \%$, $14)$, neurosurgery $(6.4 \%, \mathrm{n}=22)$, endocrinology $(9.0 \%, \mathrm{n}=31)$.

\subsection{Statistical Analysis}

Frequency and descriptive statistics were generated for each of the variables contained in the instruments.

Psychometric properties of the PCQ-P are established prior to full examination of the statistics. Aggregated mean scores were calculated for established factor scores and correlations between the factors calculated to examine the relationship between scores.

\subsection{Ethical Considerations}

Full ethical approval was sought and a favourable opinion was granted from the regional Research Ethics Committees representing the various hospitals. All procedures were conducted in line with the principles of the Declaration of Helsinki. 
Table 2. Frequency scores for Person-Centred Climate Questionnaire-Patients (PCQ-P)

\begin{tabular}{|c|c|c|c|c|c|c|c|c|c|}
\hline Statement & 1 & 2 & 3 & 4 & 5 & 6 & $7 \mathrm{~A}$ & $\mathrm{~B}$ & \\
\hline A place where the staff is knowledgeable. & 3.0 & 0.3 & 0.3 & 0.6 & 3.6 & 30.5 & 61.7 & 0.89 & \\
\hline $\begin{array}{l}\text { A place where I rely on } \\
\text { receiving the best care. }\end{array}$ & 3.0 & 0 & 1.2 & 0.6 & 3.0 & 21.2 & 71.0 & 0.94 & \\
\hline A place where I feel in safe hands. & 3.0 & 0.3 & 0.9 & 0.6 & 2.7 & 18.5 & 74.0 & 0.94 & \\
\hline A place where I feel welcome. & 3.0 & 0.3 & 1.2 & 0 & 1.2 & 18.5 & 75.5 & 0.96 & \\
\hline $\begin{array}{l}\text { A place where it is easy to } \\
\text { talk to the staff. }\end{array}$ & 2.7 & 0.3 & 0.9 & 0.6 & 3.9 & 18.7 & 72.9 & 0.96 & \\
\hline $\begin{array}{l}\text { A place where the staff take } \\
\text { notice of what I say. }\end{array}$ & 3.3 & 0.9 & 1.2 & 1.2 & 3.0 & 21.6 & 68.7 & 0.93 & \\
\hline $\begin{array}{l}\text { A place where the staff } \\
\text { come quickly when I need help. }\end{array}$ & 2.7 & 0.9 & 1.5 & 1.8 & 6.9 & 21.5 & 64.7 & 0.88 & \\
\hline $\begin{array}{l}\text { A place where the staff use } \\
\text { language I can understand. }\end{array}$ & 3.0 & 0.0 & 0.6 & 0.6 & 3.3 & 26.3 & 65.9 & 0.85 & \\
\hline A place which is neat and clean. & 2.4 & 06 & 1.2 & 0.9 & 3.6 & 19.8 & 71.4 & 0.85 & \\
\hline $\begin{array}{l}\text { A place where the staff have } \\
\text { time for the patients. }\end{array}$ & 2.7 & 1.2 & 1.5 & 0.9 & 4.6 & 22.5 & 66.6 & 0.89 & \\
\hline $\begin{array}{l}\text { A place which feels homely even though } \\
\text { I am in a Hospital. }\end{array}$ & 2.7 & 2.7 & 0.6 & 4.5 & 6.7 & 22.7 & 60.0 & & 0.87 \\
\hline $\begin{array}{l}\text { A place where it is possible to get unpleas } \\
\text { ant thoughts out of your head. }\end{array}$ & 3.6 & 3.6 & 2.0 & 12.1 & 11.5 & 28.2 & 39.0 & & 0.80 \\
\hline $\begin{array}{l}\text { A place where the people talk about ordinary } \\
\text { things, not just illness. }\end{array}$ & 2.8 & 1.3 & 0.6 & 3.5 & 4.7 & 33.8 & 53.0 & & 0.78 \\
\hline $\begin{array}{l}\text { A place where the staff make a little extra } \\
\text { effort on my behalf. }\end{array}$ & 3.2 & 1.3 & 0.6 & 2.9 & 3.5 & 27.0 & 61.6 & & 0.89 \\
\hline $\begin{array}{l}\text { A place where I have choices, } \\
\text { for example, what to do. }\end{array}$ & 4.2 & 1.3 & 2.2 & 8.0 & 9.9 & 26.9 & 47.4 & & 0.85 \\
\hline $\begin{array}{l}\text { A place where there is } \\
\text { something nice to look at. }\end{array}$ & 5.5 & 4.8 & 6.8 & 14.8 & 10.3 & 20.3 & 37.6 & & 0.76 \\
\hline $\begin{array}{l}\text { A place where I can get } \\
\text { "that little bit extra". }\end{array}$ & 4.2 & 2.3 & 2.3 & 8.1 & 6.8 & 26.5 & 50.0 & & 0.91 \\
\hline
\end{tabular}

Table 3. Descriptive statistics and measures of homogeneity of scores of standardised instruments

\begin{tabular}{llllr}
\hline & Mean scores & Skewness & Kurtosis & Measures of homogeneity \\
\hline Safety & 6.43 & -3.60 & 13.80 & 0.964 \\
Hospitality & 5.90 & -1.92 & 4.00 & 0.918 \\
Total PCQ-P Score & 6.21 & -2.93 & 9.65 & 0.958 \\
Patient Experience Questionnaire & 0.23 & 1.27 & 1.25 & 0.824 \\
\hline
\end{tabular}

\section{RESULTS}

As concerns the Picker Patient Experience Questionnaire, Table 1 indicates that the majority of patients felt that they had no problems with the care provided. The majority of patients felt they were treated with dignity and respect while in the hospital (95.8\%), their pain was managed appropriately (88.9\%). However almost half of the patients stated that they wished to be more involved in decisions made about their care and treatment $(47.1 \%)$.

Patients were asked to indicate their level of agreement on the 17 items contained in the Personcentred Climate Questionnaire (Patient). Examination of the items (Table 3) indicates that the majority of patients were positive about the presence of a personcentred climate. Two thirds of the items (all relating to the construct 'Safety') scored above 95\% agreement 
whereas the seven items relating to 'Hospitality' were scored positively to a slightly lesser extent. The least positively scored item was 'A place where there is something nice to look at' with $30.2 \%$ of patients disagreeing. Negative scores on the remaining five variables ranged from 5.9-15.8\% Table 2.

Bartlett's test of Sphericity and Kaiser-MeyerOlkin's (KMO) measure of adequacy were calculated to evaluate the appropriateness of the correlation matrix for factor analysis (Brace et al., 2006). Bartlett's test of sphericity is significant (chi-square 5716, df $=136$, $\mathrm{p}<0.001$ ) and KMO value of 0.96 is considered indicative of a factorable data set.

Confirmatory Factor Analysis using continuous data and Maximum Likelihood Robust extraction with Varimax Rotation was used to test the two factor measurement model. Examination of the PCQ-P items indicated non-normal distribution across items therefore Maximum Likelihood Robust extraction for confirmatory factor analysis was recommended (Muthén and Muthén, 2012) in addressing issues of deviation from normality of items. Hopper et al. (2008) identify acceptable fit statistics as RMSEA scores below 0.06, 90\% RMSEA upper range below 0.08 and Confirmatory Fit Index above 0.95. The fit statistics confirm the acceptability of the model (Chi-square 251 , df $=118, \mathrm{p}=0.00$; RMSEA $0.058,90 \%$ RMSEA 0.048-0.068, CFI = 0.956).

Using guidelines provided by Hair et al. (2006) in the identification of factor loadings appropriate to the sample size $(\mathrm{n}=345)$ a threshold of 0.4 was considered as acceptable and all factor loading were acceptable Table 2 . The two factors accounted for $77.5 \%$ of the data variance. Measures of homogeneity indicate a consistent pattern of scoring within factor items and for the total PCQ-P. Cronbach's Alpha values for each factor were very high and may indicate narrowness in the items to measure the construct Table 3 but acceptable.

The scores for each of the variables contained in the factor were aggregated to create a mean score per construct. Examination of the mean scores indicates that patients scored both constructs of the PCQ-P and the total score favourably. Patients felt that they were in a safe environment scoring it at 6 out of 7 , indicating a strong sense of agreement with the presence of the factor. Similar scoring was reported for the construct 'Hospitality' Table 3. Measures of skewness and kurtosis on the factors and total score of the PCQ-P indicate a scoring pattern that is a departure from normal distribution Table 3 .
Analysis of the scoring across the questionnaire total mean scores according to hospital setting (and also specialities) found no significant differences with the exception of across patient's experience (2.564, df $10,207, \mathrm{p}=0.006)$. Post hoc Scheffe tests, accounting for multiplicity, fail to identify statistically significant differences according to settings. All settings (and therefore specialities) respond in a similar pattern.

Examination of the correlations between two factor scores and overall score of the PCQ-P and the Picker PPE-15 indicate that this is a moderate and statistically significant relationship between the factors. This is a negative relationship where higher scores on the PCQ-P are associated with lower levels of problem reporting by patients (as measured by the Picker PPE-15). The relationship between personcenteredness and patient experience was stronger when examining the relationship between the total survey scores as displayed in Table 4.

\section{DISCUSSION}

Primarily the findings relating to the PCQ-P confirms the appropriateness of conducting a factor analysis. In addition it confirms the presence of a two factor model. This is a replication of the factor structure reported by Edvardsson et al. (2009) in the original analysis of the English version of the questionnaire and a slight departure from the three factor model reported in the Swedish study Edvardsson et al. (2008) which reported the factor hospitality split into two factors. The factor 'safety' is consistent in both studies.

Examination of the relationship between the emergent factors shows a high correlation between the two constructs contained in the PCQ-P. This would indicate the presence of collinearity and points to the existence of a single overarching construct of personcentredness. This is further confirmed by the high measures of homogeneity reported in this study and others (Edvardsson et al., 2008; 2009) and the justification of the aggregation of the item scores to an overall total score. However, the confirmatory factor analysis supports a two factor model. The presence of high measures of skewness and kurtosis for the constructs and overall instrument raises questions regarding the stability of the instrument. Further analysis and testing of the instrument is required to clarify the factor structure and how the instrument should be best used in future research. Patients reported high levels of agreement with many of the items contained in the questionnaire. 
Randal Parlour et al. / International Journal of Research in Nursing 5 (1): 27-36, 2014

Table 4. Correlation scores between the PCQ-P and the Patient Experience Questionnaire (PPE-15) (**indicates p<0.01)

\begin{tabular}{lllll}
\hline & Safety & Hospitality & Total PCQ-P score & Patient experience questionnaire \\
\hline Safety & 1.0000 & & & \\
Hospitality & $0.795^{* *}$ & 1.000 & \\
Total PCQ-P Score & $0.961^{* *}$ & $0.935^{* *}$ & 1.0000 & \\
Patient experience questionnaire & $-0.365^{* *}$ & $-0.390^{* *}$ & $-0.359^{* *}$ & 1 \\
\hline
\end{tabular}

There were lower levels of agreement on 4 items that related to the aesthetics of the hospital, management of unpleasant thoughts and the provision of choice yet this was still scored as having high levels of agreement. Interestingly all four items were within the construct 'Hospitality'. Given the relative newness of the PCQ-P there is limited comparative data to benchmark the findings against however the inclusion of the PPE-15 provides supplementary data.

The Picker PPE-15 is an internationally accepted measure of quality care (Jenkinson et al., 2002). It has proven psychometric properties (Jenkinson et al., 2003; Wolf et al., 2012) and the measures of homogeneity in this study support these findings. It is used to establish clear markers of where care can and should be improved in hospital settings including the acute sector (Jenkinson et al., 2002; 2003). The findings reported here indicate that there is scope for improvements in the provision of care as there was considerable variability in the acute settings sampled. This is similar to the findings reported by Jenkinson et al. (2002). Interestingly, in the findings there existed a juxtaposition where the patients reported that they were treated with respect and dignity yet they clearly wished to be more involved in decisions made about care and treatment. This runs contrary to much of the current research literature on person-centred care that associates respect and dignity with involvement in care. In this study the Picker PPE-15 provided a valuable measure of quality of care in the acute sector clearly indicating areas for improvement.

Edvardsson et al. (2009) recommended the use of the PCQ-P as a starting point for studies aiming to explore associations between person-centred care and health outcomes in hospital patients. The correlation scores demonstrate a clear linkage between the presence of a positive person-centred climate and the provision of good quality care in the acute setting. The strength of the relationship between the two is moderate where a positive person-centred climate is associated with higher levels of satisfaction with patient care. Deducing the significant relationship between climate and outcomes, it can be assumed that the creation of an environment that promotes person-centredness produces improvements in patient experiences and the quality of care. This provides clear statistical evidence of the relationship between person-centred care and quality care and confirms that it is measurable in a quantitative manner. The findings reported here indicate that person-centred climate as viewed by patients is measurable and that the instrument can be used to measure the impact of interventions that aim to promote a person-centred environment.

\section{LIMITATIONS}

The high scores on the PCQ-P coupled with the measures of skewness and kurtosis for both constructs and the overall instrument are indicative of a potential ceiling effect occurring in scoring. This is a problem encountered by many instruments used to measure patients' satisfaction with care. This problem is not as pronounced in the Patient Experience Questionnaire however this may be in part due to the different scoring systems employed in both instruments. The high levels of skewness and kurtosis indicate a departure from a normal distribution and limit further statistical analysis. The ceiling effect would also limit the use of the instrument in gauging change over time. Further testing is required to confirm the factor structure of the PCQ-P.

\section{CONCLUSION}

The findings from this study provide statistical evidence of the relationship between the provision of person-centred care and positive patient experience. The instruments used in the study have proven and acceptable psychometric properties. In this study, PCQ-P constructs 'Safety' and 'Hospitality' were scored very high indicating high levels of personcentred care received on both constructs using the PCQ-P. These findings are supported by the moderate correlation between the PCQ-P and the Picker PPE-15 where higher levels of perceived person-centred care are statistically associated with less perceived problems with care. In conclusion, the instruments are appropriate for the measurement of patient care and there is a clear linkage between the provision of person-centred care and patient outcomes. 


\section{ACKNOWLEDGEMENT}

This research was supported by the Office of the Nursing and Midwifery Services Director. Correspondence concerning this article should be addressed to Dr. Paul Slater, Institute of Nursing and Health Research, Room 12J12, University of Ulster, Shore road. Newtownabbey, Belfast. Northern Ireland.

\subsection{Author's Contributions}

All authors equally contributed in this study.

\subsection{Ethics}

Full ethical clearance was sought prior to study commencement and approval was granted via the relevant Research Ethics Committees. Patient and staff information leaflets and written consent forms were provided to all participants to meet the ethical requirements of the study.

\section{REFERENCES}

ABA, 2009. Professional guidance for nurses working with older people. Dublin, An Bord Altranais.

Brace, N., R. Kemp and R. Snelgar, 2006. SPSS for Psychologists. 3rd Edn., Palgrave MacMillan, Australia, ISBN-10: 1403987874, pp: 450.

Brownie, S. and S. Nancarrow, 2013. Effects of personcentered care on residents and staff in aged-care facilities: A systematic review. Clin. Intervent. Aging, 8: 1-10. DOI: 10.2147/CIA.S38589

Clisset, P., D. Porock, H. Rowan, J. Harwood and R.F. Gladman, 2013. The Challenges of achieving person-centred care in acute hospitals: A qualitative study of people with dementia and their families. Int. J. Nurs. Stud.

DOI: 10.1016/j.ijnurstu.2013.03.001

DH, 2001. National service framework for older people. Department of Health, London. UK.

Edvardsson, D. and A. Innes, 2010. Measuring personcentered care: A critical comparative review of published tools. Gerontologist, 50: 834-846. DOI: $10.1093 /$ geront/gnq047

Edvardsson, D., P. Sandman and B. Rasmussen, 2008. Swedish language person-centred climate questionnaire-patients version: Construction and psychometric evaluation. J. Adv. Nurs. 63: 302-309. DOI: 10.1111/j.1365-2648.2008.04709.x
Edvardsson, D., S. Koch and R. Nay, 2009. Psychometric evaluation of the english language person-centred climate questionnaire-patient version. Western J. Nurs. Res., 31: 235-244.

DOI: 10.1177/0193945908326064

Hair, J.F., W.C. Black, B.J. Babin, R.E. Anderson R.L. and Tatham, 2006. Multivariate Data Analysis. 6th Edn., Pearson Prentice Hall, New Jersey.

Hopper, D., J. Coughlan and M. Mullen, 2008. Structural equational modelling: guidelines for determining model fit. Eclect. J. f Bus. Res. Meth., 6: 53-60.

CQHCA, 2001. Crossing the Quality Chasm: A New Health System for the 21st Century. 1st Edn., Washington D.C, Institute of Medicine, National Academy Press, ISBN-10: 0309072808, pp: 360.

DH, 2012. Future Health: A Strategic Framework for Reform of the Health Service 2012-2015. Department of Health.

Jenkinson, C., A. Coulter and S. Bruster, 2002. The picker patients experience questionnaire: development and validation using data from in-patient surveys in five countries. Int. J. Quality Health Care, 14: 353-358. DOI: 10.1093/intqhc/14.5.353

Jenkinson, C., A. Coulter, R. Reeves, S. Bruster and N. Richards, 2003. Properties of the picker patient experience questionnaire in a randomized controlled trial of long versus short form survey instruments. J. Public Health Med., 25: 197-201. DOI: $10.1093 /$ pubmed/fdg049

Lehuluante, A., A. Nilsson and D. Edvardsson, 2012. The influence of a person-centred psychosocial unit climate on satisfaction with care and work. J. Nurs. Manag., 20: 319-325. DOI: $10.1111 / \mathrm{j} .1365-2834.2011 .01286 . \mathrm{x}$

Manley, K., V. Hills and S. Marriot, 2011. Person-centred care: principle of Nursing Practice D. Nurs. Standard, 6: 35-37. DOI: 10.7748/ns2011.04.25.31.35.c8431

McCance, T., B. McCormack and J. Dewing, 2011. An exploration of Person-centredness in Practice. Online J. Iss. Nurs.

DOI: 10.3912/OJIN.Vol16No02Man01

McCormack, B. and T. McCance, 2010. Person-centred Nursing: Theory and Practice. 1st Edn., John Wiley and Sons, Oxford: Wiley Blackwell, ISBN-10: 1444347713, pp: 208.

McCormack, B., 2003. A conceptual framework for person-centred practice with older people. Int. J. Nurs. Practice, 9: 202- 209. DOI: $10.1046 /$ j.1440-172X.2003.00423.X 
McCormack, B., B. Karlsson, J. Dewing and A. Lerdal, 2010. Exploring person-centredness: A qualitative meta-synthesis of four studies. Scandinavian J. Caring Sci., 240: 620-634.

DOI: $10.1111 / \mathrm{j} .1471-6712.2010 .00814 . \mathrm{x}$

McCormack, B., J. Dewing and T. McCance, 2011. Developing person-centred care: Addressing contextual challenges through practice development. Online J. Iss. Nurs.

DOI: 10.3912/OJIN.Vol16No02Man03

Muthén, L.K. and B.O. Muthén, 2012. Mplus User's Guide. 6th Edn., Los Angeles, CA: Muthén and Muthén.

Olsson, L., E. Hansson, I. Ekman and J. Karlsson, 2009. A cost-effectiveness study of a patient-centred integrated care pathway. J Adv. Nurs., 65: 16261635. DOI: 10.1111/j.1365-2648.2009.05017.x
Slater, P., 2006. The development and testing of a valid and reliable nursing outcomes instrument. Unpublished $\mathrm{PhD}$ thesis. Jordanstown, Northern Ireland: University of Ulster.

Williams, G.C., M. Lunch and R.E. Glasgow, 2007. Computer-assisted intervention improves patientcentered diabetes care by increasing autonomy support. Health Psychol., 26: 728-734. PMID: 18020845

Wolf, A., L. Olsson, C. Taft, K. Swedberg and I. Ekman, 2012. Impacts of patient characteristics on hospital care experience in 34,000 Swedish patients. BioMed. Central Nurs., 11: 8-8.

DOI: $10.1186 / 1472-6955-11-8$ 